\title{
Code-switching in Malaysian Chinese Community in The Film the Journey (2014)
}

Wan Ainaa Atiqah Mohd Ismadi, Nur Nafishah Azmi, Tan Khye Chuin, Heng Wen Zhuo

To Link this Article: http://dx.doi.org/10.6007/IJARBSS/v11-i1/8412

DOI:10.6007/IJARBSS/v11-i1/8412

Received: 02 November 2020, Revised: 30 November 2020, Accepted: 18 December 2020

Published Online: 10 January 2021

In-Text Citation: (Ismadi et al., 2021)

To Cite this Article: Ismadi, W. A. A. M., Azmi, N. N., Chuin, T. K., \& Zhuo, H. W. (2021). Code-switching in Malaysian Chinese Community in The Film the Journey (2014). International Journal of Academic Research in Business and Social Sciences, 11(1), 82-95.

\section{Copyright: @ 2021 The Author(s)}

Published by Human Resource Management Academic Research Society (www.hrmars.com)

This article is published under the Creative Commons Attribution (CC BY 4.0) license. Anyone may reproduce, distribute, translate and create derivative works of this article (for both commercial and non-commercial purposes), subject to full attribution to the original publication and authors. The full terms of this license may be seen at: http://creativecommons.org/licences/by/4.0/legalcode

Vol. 11, No. 1, 2021, Pg. 82 - 95

Full Terms \& Conditions of access and use can be found at http://hrmars.com/index.php/pages/detail/publication-ethics 


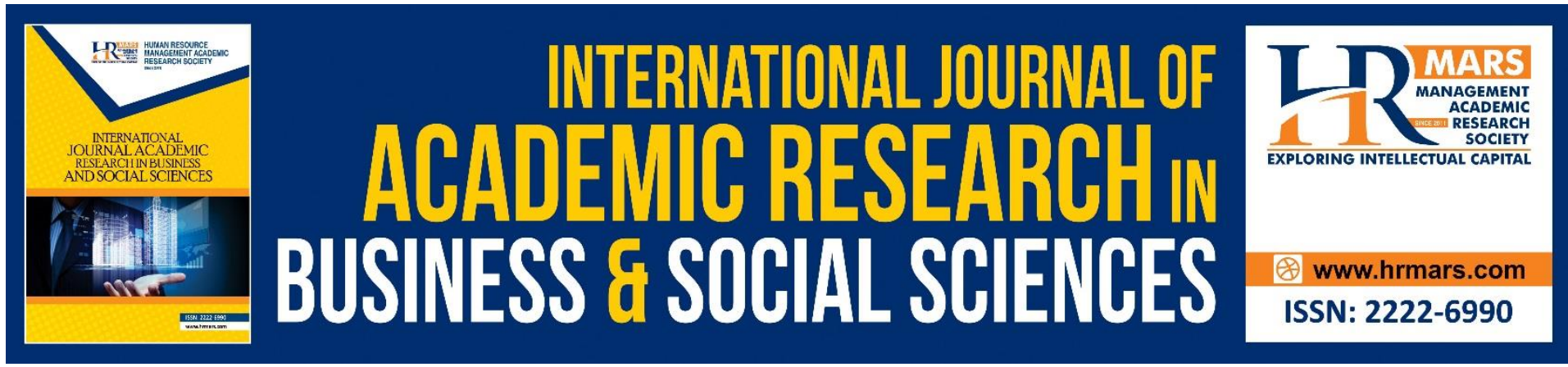

\title{
Code-switching in Malaysian Chinese Community in The Film the Journey (2014)
}

\author{
Wan Ainaa Atiqah Mohd Ismadi, Nur Nafishah Azmi \\ Faculty of film, theatre and animation, universiti teknologi mara, malaysia \\ Email: atiqah5824@uitm.edu.my,nafishah2610@uitm.edu.my
}

Tan Khye Chuin

Faculty of social science and humanities, universiti tunku abdul rahman, malaysia

Email: Tankc@tarc.edu.my

\section{Heng Wen Zhuo}

School of humanities, universiti sains malaysia

Email: Brightonheng@hotmail.com

\begin{abstract}
Code-switching is a common phenomenon especially in a multilingual nation like Malaysia. The amalgamation of its multiracial citizens such as the Malays, Chinese, Indians and others, indirectly affects the use of language and communication strategy among the people. While some researchers believe that code-switching is an evidence of lacking language knowledge, others suggested that code-switching is used as a supplementary resource to achieve particular interactional goals with other speakers. This study examined the code-switching phenomenon among Malaysian people, specifically the Chinese community. The phenomenon was observed in a film entitled The Journey (2014), whereby relevant scenes were selected, and the conversations were analysed using the framework from Malik's (1994) functions of code-switching. It was found that code switching was subconsciously or consciously employed as a vital communication strategy to convey the speakers' intended message, whether emotional or merely to provide information. Through speaking the dialects as their ancestors or they themselves have carried with them from their 'homeland' China and passed down to the current generation, they are in a sense retaining and maintaining their ethnic identity, and foster an intimate link with China, whether imagined or real.
\end{abstract}

Keywords: Code-Switching, Malaysian Chinese, Multilingual, Communications, Film

\section{Introduction}

Code-switching is a common phenomenon especially in a multilingual nation like Malaysia. The amalgamation of its multiracial citizens such as the Malays, Chinese, Indians and others, indirectly affects the use of language and communication strategy among the people. The ability to alternate two or more languages in a conversation shows that most Malaysians are proficient in multiple languages. While some researchers believe that code-switching is an 
evidence of lacking language knowledge, others suggested that code-switching is used as a supplementary resource to achieve particular interactional goals with other speakers (Chuchu, 2007). This study intended to examine code-switching phenomenon among Malaysian people, specifically the Chinese community. The phenomenon was observed in a film entitled The Journey (2014), whereby relevant scenes were selected, and the conversations were analysed using the framework from Malik's (1994) functions of codeswitching.

\section{Chinese Community in Malaysia}

The implementation of national language policy in 1970 has restructured the education system in Malaysia. Malay language is the national language of Malaysia to promote national unity among diverse ethnicities. However, the public primary schools have given a choice to choose among three languages: Malay, Mandarin and Tamil as medium of instruction. This policy has formed Malay medium school which is known as national school while Mandarin and Tamil primary schools which are known as national type school or vernacular schools. Although the main medium of instruction is varied, all the public schools shared similar teaching syllabus. Vernacular schools are served to preserve the indigenous language as well as reinforcing value and tradition of respective culture. However, all secondary public schools are required to use Malay language as the medium of instruction. The Chinese represent about $22.6 \%$ of the total population in Malaysia (Cultural Atlas, 2010).

Although Mandarin is the standard languages of Chinese as well as medium of instruction in Chinese schools but Chinese do speak other dialects such as Cantonese, Mandarin, Hokkien, Hakka, Hainan and Foochow. Chinese culture is exceptionally complex as it can be further categorized into sub grouping of ethnicity as the language source of dialects is derived from different region of China. Chinese are bounded with various dialect and they view the dialect spoken as expression of ethnic culture and identity. Yow (2005) further asserted that Chinese communities in Malaysia constitute their identities through the dialect spoken as these ties them to the cultural practice and religious belief perform by the specific region in China. Therefore, by speaking the dialect from homeland China, Chinese build a strong sense of ethnic Chinese and this will in return strengthen the feeling of intimacy to China. Therefore, it can be argued that through speaking the dialects as their ancestors or they themselves have carried with them from their 'homeland' China and passed down to the current generation, they are in a sense retaining and maintaining their ethnic identity, and foster an intimate link with China, whether imagined or real.

Malaysian Chinese maintain a distinct communal identity as an ethnic and cultural group. Although they consider themselves as Malaysians, they hold on very firmly to their culture, traditions and language. Mandarin is the common language spoken by most Chinese of recent generations while the older generation might converse in one of the many Chinese dialects (Chuchu, 2007). The Malaysian Chinese views the learning of Mandarin as preservation of Chinese cultures and is used to strengthen their Chinese identity (Pakninrat, 2006). However, as Malaysian education system requires all Malaysian to learn Malay as national language and English as second language in schools, Malaysian Chinese are consequently also capable of conversing in both Malay and English (Omar, 2007). In a multilingual community, people often switch from one language to another in their daily conversations (Shin, 2007). The choice between languages carries interactional force or implies something about the situation or the 
interlocutors. One language may be used for some social functions or in a specific social context, while another language is reserved for other functions and contexts (Meyerhoff, 2006). The ability to speak multiple languages affects how Malaysian Chinese code-switch in certain occasion; to match with person they are talking to and the circumstances they are facing. The choices that speakers make show how they represent themselves to the other person and their identity that they want to portray.

In the recent years, several researches studying code-switching occurrences has been undertaken (Barnes, 2012; Zurina, \& Shamala, 2012; Lee, et al., 2012; Si, 2010, and Sailaja, 2011). However, these studies are mainly of exploratory nature with only a scant number providing insightful conclusions. Among film studies on code-switching found, a mere two focused on Malaysian movie. Lee et al. (2012) who analysed code-switching occurrences in the Malaysian movie Sepet (2005) directed by the late Yasmin Ahmad, found it to be one of the essential strategy used in communication among young Malaysians, and asserted that 'code-switching practice is inevitable in countering communication problem during conversation among Malaysian' as they comprise mostly of multilingual speakers. The significance of this particular research seems to lie more in illustrating how young Malaysians code-switch by drawing examples from the movie and analysing them, thus providing readers who are not familiar with Malaysian culture a glimpse of the nature of code-switching in Malaysian setting. Despite not being ground-breaking, it is still a fairly interesting read. Another published study on Malaysian movie Gol \& Gincu by Zurina and Shamala (2012) was unfortunately invalid, with no research questions, obvious flaws in referencing and poor justification for research designs.

Another code-switching study on film by Barnes (2012) employed a different approach in using 'Markedness Model' to examine how 'code-switching marks the distinction between the insider and the outsider', in other words, how code-switching reinforces the notion of 'us' and 'them'. Barnes maintained that marked language contribute greatly to the creation of outsider identity, an example would be that within a Greek community, Greek as the marked language may be used to exclude an English speaker, who is viewed as an outsider.

Si (2010) claimed that much research on code-switching has been synchronic and there is a need to conduct a diachronic investigation, which he/she done it through analysing seven Bollywood movies spanning the last three decades of the Indian film industry to discover the linguistic changes over this period. Movies of similar settings, plots and themes were carefully selected to ensure comparability between them. Aung Si maintained that the amount of codeswitching involving English from movies has increased dramatically and this indicated that English has been used more frequently in recent years, although it may not be conclusive.

Sailaja (2011) who analysed a Hindi film 'Jab We Met' found Hinglish (Hindi-English) codeswitching occurrences scattered throughout the movie in a completely natural manner. Sailaja concluded by claiming that the film reflects the Hinglish code-switching in India, thus suggesting the possibility of a true linguistic representation via film, which is imperative if film analysis is to have high regard within the field of sociolinguistic studies. Against this optimistic view, Si (2010) warned caution if the findings from movies are to be extrapolated to realworld situations as the data is from fictional sources. However, Si then went on to explain that the significance of results from studying films 'lies not in providing precise description of complex sociolinguistic phenomena' (p.405) but in suggesting broad trends and novel 
hypotheses, which can then be tested through reliable field data. In conclusion, codeswitching studies on films have until present demonstrated the capacity of film to exemplify language usage in real life.

Although the research on code-switching has been done intensively in the past, most language scholars have examined these issues more in a face-to-face interaction rather than in fictional contexts. In Malaysia, researches tend to focus on the interaction of students and teachers in classrooms (Lin, 2008). While extensive studies have been done to explain the linguistic phenomenon in actual verbal interaction, scant attention has been given to the area of code-switching in other mediums such as films. Linguistic studies of fictional conversations are relatively rare, and similarly, there has been a tendency for film scholars to devote little attention to dialogue analysis (Bleichenbacher, 2008). Hence this research attempts to fill this gap by analysing the functions and reasons for code-switching among Malaysian Chinese community through film. According to Bleichenbacher (2008), film as a genre of fictional study has been found to be the most appropriate medium to represent the 'richness and complexity of real-life multilingual realities' (p.12). It can be seen that some recent Malaysian film portrayed the identity of its multiracial citizens by applying code-switching in the characters' conversations and reinforce the idea that film is a reflection of reality. Hence, for movies produced in Malaysia where the characters interact in code-switching, it can provide insight into the psyche of Malaysians (Lee, Chong, \& Arif, 2012). As Gumperz (1982) emphasized, close analysis of brief spoken exchanges is necessary to identify and describe the functions of code-switching. Therefore, in understanding the reasons of code-switching among Malaysian Chinese Community, a close study was conducted by looking at selected scenes from the film The Journey. This study aims to analyse the occurrence of code-switching among the characters in the film and to study the functions of code-switching among Malaysian Chinese community that are reflected in the film The Journey (2014).

\section{Code Switching}

According to Grosjen (1982), code switching is the usage of two or more linguistic varieties in the conversation that can be seen in bilingual community. The alternation of two or more languages can be observed in the daily interaction of bilingual community. Bullock \& Toribio, (2009) contended that code switching takes place in the bilingual community where the speakers shift from one language to another within the same utterance in an unchanged setting. Blom and Gumperz (1972) further divided code-switching into two categories which are situational and metaphorical. Situational code switching refers to selection of language which is dependent on the social situation. For instance, changes in participant, topic and even setting will influence the choice of language used by the speakers. In contrast, metaphorical code switching stated that the code switching is driven by conversational strategy. In other words, metaphorical code switching is employed to assist conversational acts such as an apology, request, complain and others (Blom, \& Gumperz, 1972). Extensive researches have been done on the motivation and function behind code switching. Code switching is often viewed as language incompetency of particular language users but some researchers challenge this notion. For instance, Heller (1988) asserted that the occurrence of code switching might not merely due to language deficiency. He argued that there are a lot factors that contributed to the code switch among the language users. For instance; identity, solidarity and ethnicity can all contribute to code switching. 
The present research paper has chosen Malik (1994) ten reasons of code switching as the framework to study the function of verbal discourse in the movie. This model is widely accepted to clarify the motives behind code switching in sociolinguistic approach. Malik (1994) categorized code switching into ten reasons that look into a variety of motivation and purposes that prompted a speaker to switch code during the social interaction. This particular model is clear, understandable and can be applied into Malaysia context.

1. Lack of Facility: Bilingual speakers tend to switch code when certain concepts do not exist in the language in order to avoid misunderstanding.

2. Lack of Register: Code switching occurs when the bilingual speakers are not equally competent in both languages as they are having difficulty in choosing proper words in the target language to express the meaning.

3. Mood of the Speaker: The mood of the speaker such as sad, angry and nervous will affect the selection of the code because the words in other language will take less effort to convey the emotion at that particular moment.

4. To emphasize a point: Code switching takes place when the speakers are intended to highlight certain arguments in their speech.

5. Habitual Experience: Bilinguals have tendency to code switch when they come across with fixed phrases such as greeting, apologies, commands and other conversational acts.

6. Semantic significance: Bilingual code-switch to express semantically significant information as well as social information.

7. To show identity with a group: Code switching takes place when the speakers intended to show a sense of belonging and familiarity toward a particular group that shares the similar identity, value, culture, or ethnicity.

8. To address a different audience: Bilingual speakers will switch to another variety in order to communicate with others group of listeners or audience.

9. Pragmatic reasons: The context of the conversation such as formality, participants, location will influence the code-switching behavior from the bilingual speakers.

10. To attract attention: Code switching occurs for the purpose of gaining attention from the speaker.

\section{Research Methodology}

In order to explore code-switching within Malaysia Chinese community, a movie entitled The Journey (2014) has been selected as the subject of research, primarily because it provides ample examples of code-switching within this particular community, as will be discussed later. This film produced by Astro and directed by Chiu Keng Guan made almost RM18 million at the cinema was an enormous hit (Hassan, 2014). It tells the story of a newly engaged couple, Malaysian Chinese woman (Bee) and her fiancé (Benji) from England, who came back to Malaysia seeking the blessing of Bee's father. Bee who was sent to English by force, has been living there since the age of eight. Hence, she was fluent not only in the local languages but also English, and many instances of her code-switching can be observed. Benji, on the other hand, an Englishman who obviously does not speak the local languages were at pains trying to break down the linguistic and cultural barrier. However, the true star of the movie was neither one of them but Bee's father (Uncle Chuan), a conservative man who at first refused to accept Benji as his son-in-low. Uncle Chuan's insistence on sending wedding invitation personally to his former classmates spurred a long trip with Benji to deliver the invitation 
cards and along the course, both acquired a deeper understanding and respect for other's culture and language.

Film analysis as this study is doing, inevitably has to justify how the film reflects real life to validate the significance of the study. In the case of The Journey (2014), we wish to argue that the film has reflected Malaysian Chinese community to a certain extent. This reflection of reality was evident through the inclusion of various roles of Mandarin speakers, and many speakers of two Chinese dialects (Cantonese and Hokkien). The two leading roles, Bee and Benji who speaks English and sometimes code-switch further reflects the reality of the community, Ah Bee represented Malaysian Chinese who are heavily influenced by the English culture and language, and Benji represented a foreign Englishman who are integrating into the Malaysian Chinese culture. The great popularity of the film also obliquely confirms this mirroring of reality, as the settings, cast and language used resonates with the local community, thus was able to reach a wide audience as suggested by the large revenue in cinema.

As with most film analysis, the argument of the film reflecting reality has its limitation. For instance, Hokkien and Cantonese speakers are not the only Chinese dialects speakers within Malaysian Chinese community, Teochew and Hakka speakers for example were neglected and not represented in the film. Moreover, the script was written for the consumption of broad audiences with obvious commercial reason, thus there might be instances where language used are deliberately exaggerated or even distorted to cater to the taste of the audience, which are mainly Malaysian. The data for the purpose of this study will naturally be from the movie The Journey (2014). The movie was viewed multiple times, and scenes involving code-switching are transcribed and translated (see Appendix A). As three languages (Mandarin, English and Malay) and 2 Chinese dialects (Cantonese and Hokkien) were employed in the movie, the task of transcribing the film was not without a hitch. For clarity, differentiation between languages and dialects is imperative. To do so, a transcription format has been devised to serve the occasion. Of all the dialogues in the film which were selected to transcribe, English will be italicized, Standard Mandarin, also known as Pu Tong Hua will be written in simplified Chinese, while other Chinese dialects will be transcribed according to their sounds. Despite the fact that it is possible to transcribe one of the Chinese dialects, namely Cantonese, into simplified Chinese, it was decided against it for fear of confusion with the standard Mandarin as they share the same orthographical system. At the end of each exchange, the language or dialect spoken will be stated in bracket e.g. [English/Cantonese]. Translation will also be provided below every exchange for readers who may not be familiar with the languages and dialect present in the film.

Nine extracts from the movie transcript will be singled out to for analysis. They were deliberately chosen for they each represent one or two reasons found in Malik's (1994) ten reason of code-switching. These extracts will be explained in terms of the function codeswitching served, and to provide rationale for why code-switching has occurred. Lastly, it is hoped that through them, genuine insights concerning code-switching within Chinese community will be gained. 


\section{Results and Discussion}

\section{Extract 1}

Bee: He didn't mean it, lei ho $m$ ho yi kong ha tou lei ah? [English, Cantonese]

(He didn't mean it; can't you be reasonable?)

Bee: I wanted to learn Chinese, hai lei bek ngo hui ying kok, now I become english, isn't that what you want? [English, Cantonese]

(I wanted to learn Chinese, it was you who forced to England, now I become English, isn't that what you want?)

In Extract 1, Bee and her father was having an argument at the dining table while they were having dinner during the eve of Chinese New Year. Her father, Uncle Chuan was unhappy as Bee came back with her English fiancé, Benji, and was not thrilled to hear their decision to get married. From this scene, we can see that, in a state anger, Bee used a lot of code-switching when speaking to her father. Malik (1994) stated that mood could be the cause of codeswitching, usually when bilinguals are anxious, tired or angry. He adds that when the speaker is in the right state of mind, he or she can find the appropriate word or expression in the base language.

"Very often he/she knows the word in both the languages ( $X$ and $Y$ ) but the language $Y$ may be more available at the point of time when the speaker has a disturbed mind. Such circumstances may create a hurdle in getting the appropriate word or phrase in the language in which the speaker may be more proficient if he is not mentally agitated," (Malik, 1994; as cited by Muthusamy, 2009:4)

Bee's native language was Cantonese (language X), but she has stayed in England for so many years, that English has become her dominant language. When she wanted to emphasise a point in her argument, like stating that she actually wanted to learn Chinese but her father sent her away, she said it in English (language $Y$ ). It was because her mind was disturbed and English was more readily available. Bilinguals may code-switch when the words in the other language seem to take less effort and time to be used at that particular moment. This example also showed that bilingual will tend to code-switch when they want to emphasise a point (Malik, 1994). When people are having an argument, they want to be heard and sought to make clear of what they are trying to say. This can be seen at the last point of what Bee said to her father. She stated that becoming 'English' was what her father wants and that she cannot be blame because of it. She wanted to emphasize that what she had become now is her father's mistake by sending her to England.

\section{Extract 2}

Aunty: Lu kong do yong yi, lu ah pa lu xing ko lu zai nya oh? [Hokkien]

(Its easy for you to say, do you know how difficult it is for your dad?)

Aunty: Lang deng lang ah, sho gong eh “孝顺” [Hokkien, Mandarin]

(What we chinese call 'filial piety')

It can be observed from Extract 2, that the Aunty who was speaking to Bee had deliberately chosen a word with semantic significance to illustrate her point. The codeswitching here from Hokkien to standard Mandarin served, in partial, the purpose of reminding Bee of her Chinese roots and culture. This is evident because the word which Aunty code-switch can be found in Hokkien as well, but using standard Mandarin will connote a 
sense of propriety and seriousness of the issue which cannot be found in the Hokkien dialect. The rationale behind this could also be that Standard Mandarin is the medium used in Chinese School and thus the prestige and formality held by it, while Hokkien has mainly been used in household and thus thought inappropriate when important message is to be conveyed.

\section{Extract 3}

Aunty: Lu eh ah cik jin ja sayang lu eh. [Hokkien, Malay]

(Your father really loves you)

Bee: Sayang? If he really loves me, he wouldn't have left me in England. [Malay, English]

(Love? if he really love me, he wouldn't have left me in England)

Malik (1994) proposed that speaker often uses certain fixed phrases in their speech due to habitual experience. Extract 3 indicated that the Aunty and Bee were engaging in intrasentential switching. Both speakers switched from their first language to Malay language by inserting the Malay word "sayang" to express the meaning of love. This is classified as habitual experience because there exists vocabulary that shares the same meaning to "sayang" in their own languages but they still preferred to use the Malay word. This can be explained by the habit of Malaysian speakers because Malaysia is a multi-ethnic country where Malay language is the national language and is widely used among Malaysian, and certain Malay words have fused successfully into the languages of other races without showing any linguistic discordance.

\section{Extract 4}

Uncle Chuan: Zan hai sui, hang mou gei yun jao pomcek. [Cantonese]

(Really bad lucky, we haven't even travel for long, and the tyre has punctured)

Repairman: Hai tyre tou wui pomcek, ho choi ge le, jao yong dou botak sin pomcek.

[Cantonese, Malay and English]

(All tyres will puncture someday, if you are lucky, you might use it till it worn out.)

Extract 4 shows similar function of code-switching as extract three where the speakers code switch due to habitual experience. Uncle Chuan and the repairman both inserted Malay words in their intra-sentential code switching. Both speakers used the Malay words such as pomcek and botak in their speeches, which is due to the habit formation in Malaysia. Malaysian frequently used the words subconsciously due to frequent exposure to the national language. Although Chinese prefer to use their mother tongue in communicating with other Chinese, nonetheless, some Malay words will be used in their speech when they come in handy. This demonstrated the unique culture of Malaysia where every ethnic group is influenced by each other and the merging of language choice happens on a daily basis.

\section{Extract 5}

Benji: Hello, hello, ah... 恭..喜发财. [English, Mandrin]

(Hello, hello, ah... Congratulations, have a prosperous year ahead) 
According to Malik (1994), the speaker will code switch for the purpose of showing identity with a group. Extract $\mathbf{5}$ shows that in this movie, Benji was involved in intra-sentential switching where he switched from English to Mandarin in order to identify himself with a group. Benji was the only foreigner in the Chinese community, therefore he tried to signal solidarity by using the addressee's first language. He used the common greeting “恭喜发财” (Kong Hei Fat Choi) during Chinese New Year when meeting other Chinese. His intention was to create a sense of closeness and familiarity toward the dominant Chinese community so that he could narrow the social distance between himself and other Chinese. His attitude was friendly and he tried very hard to integrate into the Chinese community by learning and using Mandarin to please the Chinese.

\section{Extract 6}

Motel Owner: 房间full house liao, left one more room 罢liao, 你要我给

你twenty, 二十号, you up, up, up, 直直走, 走到top, left hand side, 那间就是liao. Eh, 那个sabun 和tuala 已经in the room liao. Thank you liao. [Mandrin, English, Malay]

(The motel is almost full house, left one more room only, if you want, I can give you room twenty, you go up straight, walk till the top, the room will be at your left-hand side. Soap and towel is already in the room. Thank you).

Holmes (2008) stated that code-switching suggests speakers mixing up codes indiscriminately or due to linguistic incompetence. Hence, people use words from another language to complete their sentence to make the conversation runs smoothly. Malik (1994) explained that lack of register cause bilinguals to code-switch when they find difficulties in choosing appropriate words in the target language for specific topics and when they are not equally competent in the two languages. Extract 6 showed an example of code-switch because of lack of registry by the Chinese motel owner. The motel owner was trying to give directions to Benji and it can be seen that he had switched and mixed codes, not only between English and Chinese, but also Malay. Here, we can see that the motel owner is struggling to convey his intended message, which caused him to employ several languages all at the same time. The function here is mainly to overcome the language barrier to meaning making.

\section{Extract 7}

Uncle Chuan: Zheng man, 刘文正hai m hai ju li dou ga? [Cantonese, Mandrin]

(Excuse me, is Liu Wen Zheng living here?)

Female Neighbour: (No verbal response, but quickly lock the door instead)

Uncle Chuan: 请问, 刘文正事不是住在这里 $a h$ ? [Mandrin]

(Excuse me, is Liu Wen Zheng living here?)

Female Neighbour: Oh, lei wan go ko chiong go dai go ko 刘文正 hai mai? Kui guo nin ha, yat deng chot guok hui liu ge. mou kuo cho sap m ho, mou fan lei ge la.

[Cantonese, Mandrin]

(Oh, you are looking for the singer, Liu Wen Zheng, is it? He always goes for vacation during Chinese New Year. He won't be back till the fifteenth of Chinese lunar calendar) 
Meanwhile, in Extract 7, the intercourse between the female neighbour and Uncle Chuan exemplify the use of code-switching to attract attention as found in Malik's (1994) framework. At first, Uncle Chuan greeted the female neighbour mainly in Cantonese which elicited no response; he then switched to Mandrin, directing the exact question in a more formal code, wishing to gain the attention of the lady. The code-switching instances here also demonstrated preference marking, as employed by Li Wei, Milroy and Pong, (1992) to explain contrasting choices of language by the second speaker to mark dispreference in bilingual conversation. This is apparent in Extract 7 where the female neighbour intentionally switched code to show her dispreference in continuing this chat with Uncle Chuan as she distrusts Uncle Chuan and possibly suspected him as being criminal of some sort. This can be seen from her not greeting Uncle Chuan in the first place and then hasten to lock her doors, keeping herself safe from any trouble.

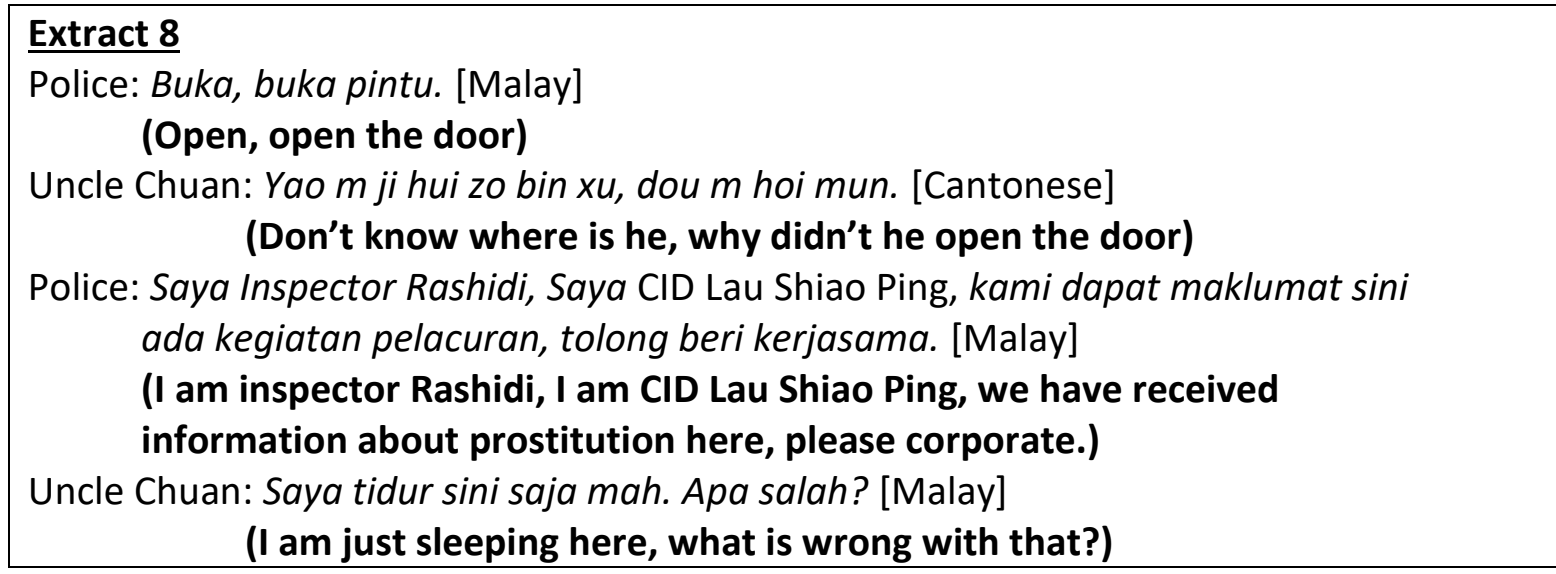

Next, it is from Extract 8 that code-switching due to pragmatic reasons can be observed. The appearance of the police in full uniform, showing their police ID and speaking the national language of Malaysia, Bahasa Malaysia all contributed to the formality of the occasion. Uncle Chuan being in such a situation was compelled to switch his code to Bahasa Malaysia in addressing the police, thus his switching of code can be perceived as necessitated by pragmatic reason.

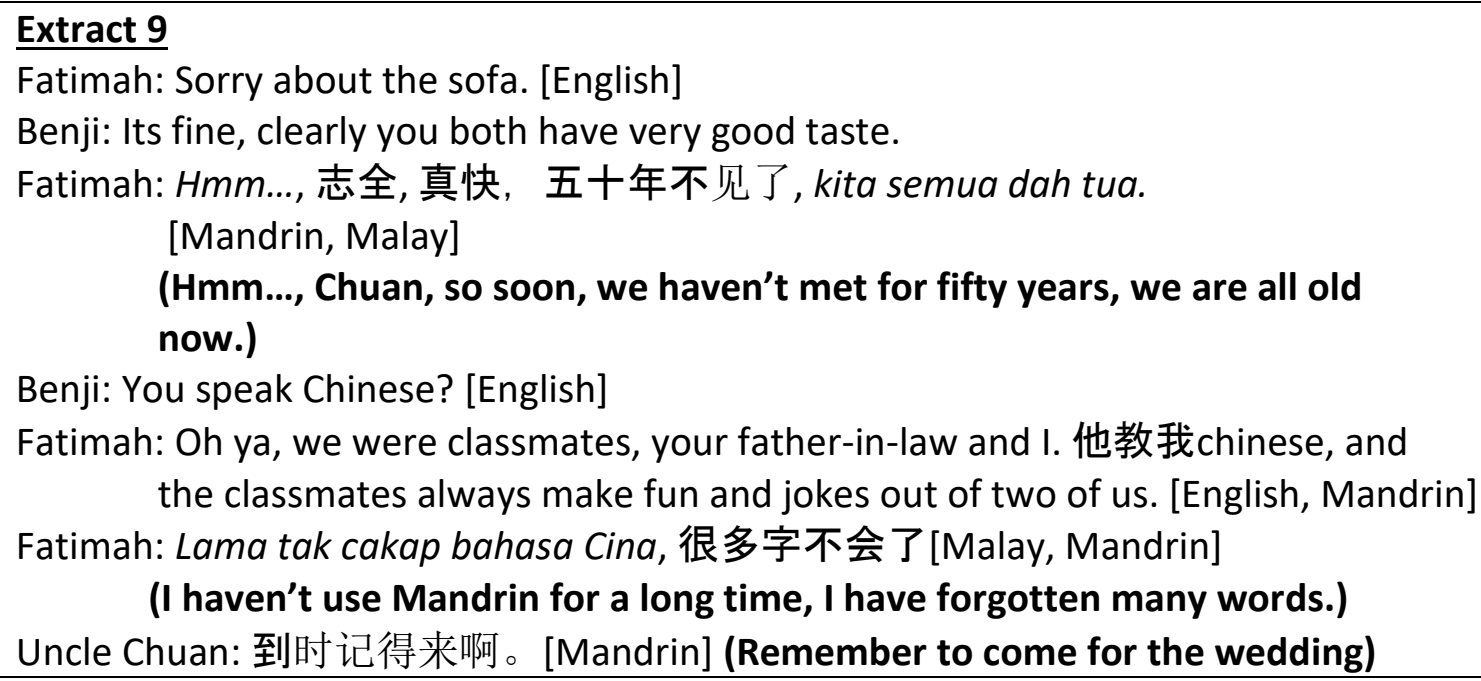

According to Malik (1994), code switching is also used when the speaker intends to address different audience, people coming from various linguistic backgrounds. This is to 
express group solidarity and commonality among the speakers. From Extract 9, we can see that Fatimah code-switch her language while talking to Benji and Uncle Chuan. She speaks in English to Benji and switch to Malay and Mandarin while talking to Uncle Chuan. Uncle Chuan also switched his code to Malay when responding to Fatimah. According to Holmes (2008), a speaker may similarly switch to another language as a signal of group membership and shared ethnicity with the addressee. Although Fatimah is not Chinese or English, she used the addressee's language to close the gap between them and to show commonality among them. She was not very good in her Mandarin anymore but attempted to speak the language as she was speaking to Uncle Chuan to show that they belong in the same group of people.

\section{Conclusion}

In short, code switching is subconsciously or consciously employed as a vital communication strategy to convey the speakers' intended message whether emotional or merely to provide information. Malaysia is a multi-ethnic country where every ethnic group employ each other's language in a flexible manner to communicate effectively. The frequent exposure of the national language in Malaysia forms a unique style of communication where Malay words are frequently utilized in everyday conversation. For speakers who are linguistically incompetent, they will switch and mix code so that their message can be understood. There are also occasion when the formality of the situation requires the speaker to code switch to another language. Regarding code-switching to Mandarin, certain connotation embedded can only be carried through Mandarin which is the prestigious and standard variety of Chinese. Speakers may also switch codes when they intend to signal solidarity toward a particular group to gain a sense of belonging. Lastly, although the findings largely corresponded to Malik's (1994) ten reasons of code-switching which is rather comprehensive, nonetheless there are some reasons which he did not cover, for example in Extract 7 where the female neighbors codeswitching to show dispreference. For future research, more in-depth investigation of code switching phenomenon found in various media should be carried out. In addition, the scope of code switching research should also be expanded to other less investigated communities such as the indigenous people in Malaysia or even foreign workers who have migrated to Malaysia. These will to yield more insights of the linguistic diversity in this multicultural and multilingual country.

\section{References}

Appel, R., \& Muysken, P. (1987). Language contract and bilingualism. Hodder and Stoughton.

Ahmad, B. H., \& Jusoff, K. (2009). Teachers' code-switching in classroom instructions for low English proficient learners. English Language Teaching. http://www.ccsenet.org/journal/index.php/elt/article/view/2363.

Barnes, L. (2012). The role of code-switching in the creation of an outsider identity in the bilingual film. Communication, 38(3), 247-260.

Blom, J. P., \& Gumperz, J. J. (1972). Social meaning in linguistic structure: Code-switching in Northern Norway. In Gumperz, J.J. \& Hymes, D. (Eds.), Directions in sociolinguistics: The ethnography of communication, 407-434. Holt, Rinehart, and Winston.

Bleichenbacher, L. (2008). Multilingualism in the movies: Hollywood character and the language choice. Hurbert \& Co.

Bullock, B. E., \& Toribio, A. J. (2009). The Cambridge handbook of linguistic code-switching. Cambridge University Press.

Chen, T. D., \& Ting, H. T. (2009). A preliminary study of teacher code-switching in 
secondary English and science in Malaysia. TESL-EJ. 13(1), (pp.1-17).

http://eds.a.ebscohost.com/ehost/detail?sid=363d48a5-3b1d.

Chuchu, D. F. (2007). Code-switching in a multilingual environment.

Universiti Pendidikan Sultan Idris.

Cultural Atlas. (n.d). Malaysian heritage. Retrieved from 10 October, 2018 from https://culturalatlas.sbs.com.au/malaysian-culture/malaysian-culture-core-concepts Grosjean, F. (1982). Life with two Languages, An Introduction to Socilinguistics. https://books.google.com.my/books/about/Life_with_Two_Languages.html?id=VqG p xZ9pDRgC\&redir_esc=y

Gumperz, J., J. (1982). Discourse strategies. Cambridge University Press.

Hassan, A. M. (2014). The Journey: A message for all Malaysian.

http://english.astroawani.com/news/show/the-journey-a-message-for-all malaysians-33181

Heller, M. (Ed.). (1988). Code-switching: Anthropological and sociolinguistic perspectives. Mouton De Gruyter.

Holmes, J. (2008). An introduction to sociolinguistics (3rd ed.). Longman.

Hornby, G. (2000) Improving Parental Involvement. Cassell.

Kachru, Y. (1989). Code-mixing, style repertoire and language variation: English in Hindu Poetic Creativity. World Englishes. 8(3).

Karen, K. Y. C. (2003). Codeswitching for a Purpose: Focus on Preschool Malaysian Children. Multilingua, 22, 59-77.

Lee, Y. L., Ng, Y. J., Chong, S. T., \& Arif, M. A. T. (2012) Code-switching in Sepet: Unveiling Malaysians' communicative styles. British Journal of Arts and Social Sciences, 6(2), 166-18.

Wei, L., Milroy, L., \& Pong, S. C. (1992) A two-step sociolinguistic analysis of codeswitching and language choice. International Journal of Applied Linguistics, 2(1), 6386.

Lim, C. S., \& Presmeg, N. (2011). Teaching mathematics in two languages: A teaching dilemma of Malaysian Chinese primary schools. International Journal of Science and Mathematics Education. 9, 137-161.

Lin, M. Y. (2008). Code-switching in the classroom: Research paradigms and approaches. Encyclopaedia of Language and Education, 3464-3477.

http://link.springer.com/referenceworkentry/10.1007/978-0-387-30424-3_260?noaccess=true.

Mahootian, S. (2006). Code Switching and Mixing. Encyclopedia of Language \& Linguistics, 2(2), 511-527.

Malik, L. (1994). Socio-linguistics: A study of code-switching. Anmol Publications Pvt. Ltd.

Meyerhoff, M. (2006). Introducing sociolinguistics. Routledge.

Muthusamy, P. (2009). Communicative functions and reasons for code switching: A Malaysian perspective. Language \& Society, 5.

Myers-Scotton, C. (1979). Codeswitching as a 'safe choice' in choosing a lingua franca. In William McCormack \& S. Wurm (eds.), Language and Society, 71-88. Mouton.

Nomura, M. (2003). Bilingualism and multilingualism: A study of code switching. Departmental Bulletin Paper, 99-111.

Omar, A. (2007). Malaysia and Brunei. In Andrew Simpson (ed.), Language and national identity in Asia, 337-359. Oxford University Press.

Pakninrat, S. (2006). Building unity through language in Malaysia: The role of Chinese 
school. Master Dissertation, Lund University.

http://lup.lub.lu.se/luur/download?func=downloadFile\&recordOId=2157980\&fileOI $\mathrm{d}=2157983$

Poplack, S. (1980). Sometimes I'll start a sentence in Spanish y termino en español: Toward a typology of code-switching. Linguistics, 18, 581-618.

Sailaja, P. (2011). Hinglish: code-switching in Indian English. ELT Journal, 65(4), 473-480.

See, S. Y., \& Ching, T. H. (2013). Mandarin as the chosen language course among learners of foreign language. A case study. Journals of Arts, Science and Commerce. 3(1), 8088.

Shin, S. Y. (2010). The functions of code-switching in a Korean Sunday school. Heritage Language Journal, $7(1)$.

$\mathrm{Si}, \mathrm{A}$. (2010). A diachronic investigation of Hindi-English code-switching, using Bollywoord film scripts. International Journal of Bilingualism, 15(4), 388-407.

Ting, M. H. (2013). Language, identity and mobility: perspective of Malaysian Chinese Youth. Malaysia Journal of Chinese Studies, 2(1), 83-102.

Yow, C. H. (2005). Weakening ties with the ancestral homeland in China: The case studies of Contemporary Singapore and Malaysian Chinese. Modern Asian Studies, 39(2), 573575.

Zurina, M. N., \& Shamala, P. (2012). Code-switching in Gol \& Gincu. Procedia- Social and Behavioural Sciences, 66, 169-175.

\section{About the Authors}

Wan Ainaa Atiqah Mohd Ismadi holds a Master of Arts (Linguistics and English Studies) from Universiti Sains Malaysia, Pulau Pinang. She is currently working as a lecturer in Writing Department at the Faculty of Film, Theatre and Animation (FiTA), Universiti Teknologi MARA.

Nur Nafishah binti Azmi holds a Master of Arts (Communication) form Universiti Sains Malaysia, Pulau Pinang (2015). Her first degree is a Bachelor of Creative Technology (Artistic Writing) from Universiti Teknologi MARA, UiTM Puncak Perdana (2010). She is currently teaching subject under the Writing Department at the Faculty of Film, Theatre and Animation (FiTA).

Tan Khye Chuin holds a Master of Arts (Linguistics and English Studies) from Universiti Sains Malaysia, Pulau Pinang. He is currently a lecturer in Universiti Tunku Abdul Rahman (UTAR), Kuala Lumpur. He instruct undergraduate students in a range of courses under Faculty of Social Science and Humanities.

Heng Wen Zhou holds a Master of Arts (Linguistics and English Studies) from Universiti Sains Malaysia, Pulau Pinang. He is currently working as Learning and Development Specialist in GPEX Central Sdn. Bhd., Penang. He is also a trainer for Cambridge Teaching Qualifications (CELT-S). 